\section{Tree pollen peaks are associated with increased nonviolent suicide in women}

\author{
Molecular Psychiatry (2005) 10, 232-235. \\ doi:10.1038/sj.mp.4001620 \\ Published online 14 December 2004
}

SIR-Research on seasonality of suicide has identified a highly replicated and robust peak in late spring and a somewhat less consistent peak in late summer and early fall. ${ }^{1}$ While a number of psychosocial and environmental factors, such as increased exposure to light in the spring, have been suggested to be associated with the spring peak, none satisfactorily explains the temporal association of the peak in suicide with the proposed environmental trigger. Based on the influence of cytokines on mood, cognition, and behavior in healthy individuals ${ }^{2}$ and patients with medical and psychiatric conditions, ${ }^{3-5}$ the reciprocal immune-brain interactions, ${ }^{6}$ and the cytokine expression during allergic reactions, we hypothesized that tree pollen (which peaks in spring) and ragweed pollen (which peaks in late summer/ early fall) may act as environmental triggers for suicide in vulnerable individuals. We explored this hypothesis by comparing the suicide rates before, during and after periods of peak atmospheric pollen.

Tree and ragweed pollen data were obtained from the American Academy of Allergy, Asthma, \& Immunology for the years 1995-1998 for the continental US and Canada. Periods of allergen exposure were derived from histograms expressing pollen counts as particles per cubic meter $\left(\mathrm{p} / \mathrm{m}^{3}\right)$ on a log scale from 0 to 1000 (y-axis) by months ( $x$-axis) within each year. Raters identified three periods for each allergen in time units of quartermonths at each location for up to 4 years divided as follows: a prepollen period (pollen counts $<10 \mathrm{p} / \mathrm{m}^{3}$ for trees and $<$ mid-way on the log scale between 1 and $10 \mathrm{p} / \mathrm{m}^{3}$ for ragweed), a peak-pollen period ( $>100 \mathrm{p} / \mathrm{m}^{3}$ for trees and $>$ mid-way on the log scale between 10 and $100 \mathrm{p} / \mathrm{m}^{3}$ for ragweed), and a postpollen period when concentrations returned to the prepollen levels. Intervals with intermediate pollen counts were discarded.

Suicide data were obtained from the General Mortality Database compiled by the National Center for Health Statistics. Each suicide was classified by county and state of occurrence, date, sex, age, and type (violent, nonviolent, other, or unknown) based on the ICD-9 codes. Suicides by other or unknown means accounted for $6 \%$ of the total. For annual rates, person-years were estimated by summing each county's population from the 2000 Census across the years of observation by sex and age categories. For the analysis of rates and relative rates (RRs) by allergen season and pollen-level period, person-years were estimated by multiplying the population for each age and sex category in each county by the total number of days in each pollen-level period ( = number of quarter months $\times$ days per quarter month (=7.6 days)) summed across years of observation and divided by 365.25 days per year.

Annual and seasonal suicide rates, RRs, and their standard errors were estimated in Poisson's regression models. RRs for each allergen season and suicide type were estimated setting the prepollen period as the referent and peak and postpollen periods as indicator variables. Since interaction by sex and age was found to be significant, rates and RRs for the effect of allergen exposure were calculated separately by the four age by sex strata. A post hoc analysis of a possible confounding effect of light (using a proxy measure, 'sunshine') was performed for the specific pollen periods that showed significant differences in suicide rates using mixed effects repeated measures ANOVA with pollenperiod and year as within-location effects.

The total population of these counties in 2000 was 37824174 (Table 1). The total number of quarter months of peak-pollen was 670 in the tree season (mean $=14.3$ ) and 476 in the ragweed season $($ mean $=9.5)$. In 92705505 person-years, 9528 suicides were recorded (rate $=10.3 / 100000$ personyears, 95\% confidence interval $(\mathrm{CI})=10.1,10.5)$ (Table 2). As in other population-based samples of completed suicide, the rate in males was greater than in females $(\mathrm{RR}=4.1,95 \% \mathrm{CI}=3.9,4.3)$, and greater in older people compared with younger $(\mathrm{RR}=1.4,95 \%$ $\mathrm{CI}=1.3,1.5)$. The rate in older males was greater than in younger males $(R R=1.8,95 \% C I=1.7,1.9)$. No difference by age was seen in females.

A total of 2417 suicides were recorded in the tree season and 1811 in the ragweed season (Table 3). During the tree allergy season, there was a two-fold increase in the rate of nonviolent suicides among younger females in the peak-pollen period compared with the prepollen period $(95 \% \mathrm{CI}=1.3,3.0)$ (Table $3)$. There was no difference between the postpollen period and the prepollen period. In older females, the rate of nonviolent suicide in the postpollen period was 4.6 times that of the prepollen period (95\% $\mathrm{CI}=1.2$, 17.8), with no increase in the peak-pollen period relative to the prepollen period (Table 3 ). It is unlikely that a greater exposure to natural light during the peak-pollen season would have spuriously increased suicide rates in younger women, because a greater suicide rate was found in the peak-pollen period, while a greater 'sunshine' was found in the postpollen period. However, in older women, it is possible that a greater light exposure during the postpollen period could have spuriously inflated the rate of suicide during that period. The differences in the tree pollen period effect between younger and older women may also represent a consequence of 
aging-related changes in the immune, endocrine, and nervous systems and their reciprocal interactions.

The hypothesized association was thus found only for nonviolent suicides, only in females, and only for tree pollen. This sex-specific finding is consistent with the previously reported increased rate of atopy in females and several reports that allergy is associated with both the occurrence and severity of depression in women but not in men. ${ }^{7}$ Yet, if our hypothesis is correct, why would it be confirmed only for tree pollen and not also for ragweed pollen? Although ragweed is the single most allergenic plant in the US, the allergenic impact of trees is greater, with greater amount of pollen produced over a longer period of exposure, as a result of a successive (partially overlapping) onset of pollination of various

Table 1 Sample characteristics

\begin{tabular}{|c|c|c|c|c|c|}
\hline Counties (n) & 60 & & & & \\
\hline \multicolumn{6}{|c|}{ Counties by years of observation (\%) } \\
\hline 4 & 27 & & & & \\
\hline 3 & 18 & & & & \\
\hline 2 & 32 & & & & \\
\hline \multirow[t]{2}{*}{1} & 23 & & & & \\
\hline & Total & Maximum & Minimum & Mean & $S D^{\mathrm{a}}$ \\
\hline \multicolumn{6}{|c|}{ County population by age and sex $x^{\mathrm{b}}$} \\
\hline Younger males & 16414303 & 1048851 & 52736 & 273572 & 227455 \\
\hline Older males & 1829557 & 123036 & 4856 & 30493 & 27260 \\
\hline Younger females & 16782129 & 1133817 & 46375 & 279702 & 239217 \\
\hline Older females & 2798185 & 177516 & 7045 & 46636 & 42784 \\
\hline Total sample & 37824174 & 2465326 & 111738 & 630403 & 534389 \\
\hline \multicolumn{6}{|c|}{ Quarter months ${ }^{\mathrm{C}}$ of high exposure by season } \\
\hline Tree $^{\mathrm{d}}$ & 670 & 34 & 1 & 14.3 & 8.6 \\
\hline Ragweed $^{\mathrm{e}}$ & 476 & 23 & 1 & 9.5 & 4.6 \\
\hline
\end{tabular}

${ }^{\mathrm{a}} \mathrm{SD}=$ standard deviation.

bopulation in 2000; younger is $<65$ years and older is $\geqslant 65$ years.

${ }^{\mathrm{c}}$ One-quarter month $=365.25$ days $/ 48$ quarters $=7.6$ days.

${ }^{\mathrm{d}} N=47$ counties.

${ }^{\mathrm{e}} N=50$ counties.

Table 2 Total suicides, person-years, rates, and relative rates by sex and age ${ }^{\mathrm{a}}$

\begin{tabular}{|c|c|c|c|c|}
\hline & Suicides & Person-years & Rate $(95 \%$ CI) & $R R(95 \% C I)$ \\
\hline Total sample & 9528 & 92705505 & $10.3(10.1,10.5)$ & \\
\hline Older-total ${ }^{\mathrm{b}}$ & 1561 & 11374019 & $13.7(13.1,14.4)$ & $1.4(1.3,1.5)$ \\
\hline Younger-total & 7967 & 81331486 & $9.8(9.6,10.0)$ & 1.0 \\
\hline Males_total & 7531 & 44694097 & $16.8(16.5,17.2)$ & $4.1(3.9,4.3)$ \\
\hline Females-total & 1997 & 48011408 & $4.2(4.0,4.3)$ & 1.0 \\
\hline \multicolumn{5}{|l|}{ Males } \\
\hline Males-older & 1273 & 4478585 & $28.4(26.9,30.0)$ & $1.8(1.7,1.9)$ \\
\hline Males-younger & 6258 & 40215512 & $15.6(15.2,16.0)$ & 1.0 \\
\hline \multicolumn{5}{|l|}{ Female } \\
\hline Females-older & 288 & 6895434 & $4.2(3.7,4.7)$ & $1.0(0.9,1.1)$ \\
\hline Females-younger & 1709 & 41115974 & $4.2(4.0,4.4)$ & 1.0 \\
\hline
\end{tabular}

${ }^{a}$ Rates per 100000 person-years; $\mathrm{CI}=$ confidence interval; $\mathrm{RR}=$ relative rates. Females and younger people are the referent groups.

${ }^{\mathrm{b}}$ Older is $\geqslant 65$ years and younger is $<65$ years. 
Table 3 Suicides, person-years of exposure, rates, and relative rates of suicide by allergen season, sex, and age ${ }^{\mathrm{a}}$

$\begin{array}{cccc}\text { Preexposure } & \text { High exposure } & \text { Postexposure } & \begin{array}{c}\text { High vs } \\ \text { preexposure }\end{array} \text { post vs } \\ \text { preexposure }\end{array}$

Suicides Person-years Rate (95\% CI) Suicides Person-years Rate (95\% CI) Suicides Person-years Rate (95\% CI) RR (95\% CI) RR (95\% CI)

\begin{tabular}{|c|c|c|c|c|c|c|c|c|c|c|c|}
\hline \multicolumn{12}{|l|}{ Tree season } \\
\hline All suicides & 958 & 9837185 & $9.7(9.1,10.4)$ & 999 & 9837185 & $10.2(9.5,10.8)$ & 460 & 4981431 & $9.2(8.4,10.1)$ & $1.0(1.0,1.1)$ & $0.9(0.8,1.1)$ \\
\hline Males-younger & 629 & 4239677 & $14.8(13.7,16.0)$ & 617 & 4239677 & $14.6(13.4,15.7)$ & 290 & 2147349 & $13.5(12.0,15.2)$ & $1.0(0.9,1.1)$ & $0.9(0.8,1.0)$ \\
\hline Males-older & 115 & 484997 & $23.7(19.7,28.5)$ & 130 & 484997 & $26.8(22.6,31.8)$ & 63 & 246643 & $25.5(20.0,32.7)$ & $1.1(0.9,1.5)$ & $1.1(0.8,1.5)$ \\
\hline Females-younger & 185 & 4362038 & $4.2(3.7,4.9)$ & 217 & 4362038 & $5.0(4.4,5.7)$ & 86 & 2206899 & $3.9(3.2,4.8)$ & $1.2(1.0,1.4)$ & $0.9(0.7,1.2)$ \\
\hline Females-older & 29 & 750473 & $3.9(2.7,5.6)$ & 35 & 750473 & $4.7(3.3,6.5)$ & 21 & 380540 & $5.5(3.6,8.5)$ & $1.2(0.7,2.0)$ & $1.4(0.8,2.5)$ \\
\hline Nonviolent suicides & 144 & 9837184 & $1.5(1.2,1.7)$ & 194 & 9837184 & $2.0(1.7,2.3)$ & 88 & 4981431 & $1.8(1.4,2.2)$ & $1.3(1.1,1.7)$ & $1.2(0.9,1.6)$ \\
\hline Males-younger & 97 & 4239677 & $2.3(1.9,2.8)$ & 105 & 4239677 & $2.5(2.0,3.0)$ & 50 & 2147349 & $2.3(1.8,3.1)$ & $1.1(0.8,1.4)$ & $1.0(0.7,1.4)$ \\
\hline Males_older & 12 & 484997 & $2.5(1.4,4.4)$ & 18 & 484997 & $3.7(2.3,5.9)$ & 12 & 246643 & $4.9(2.8,8.6)$ & $1.5(0.7,3.1)$ & $2.0(0.9,4.4)$ \\
\hline Females-younger & 32 & 4362038 & $0.7(0.5,1.0)$ & 63 & 4362037 & $1.4(1.1,1.8)$ & 19 & 2206899 & $0.9(0.5,1.3)$ & $2.0(1.3,3.0)$ & $1.2(0.7,2.1)$ \\
\hline Females-older & 3 & 750473 & $0.4(0.1,1.2)$ & 8 & 750473 & $1.1(0.5,2.1)$ & 7 & 380540 & $1.8(0.9,3.9)$ & $2.7(0.7,10.1)$ & $4.6(1.2,17.8)$ \\
\hline Violent suicides & 767 & 9867185 & $7.8(7.3,8.4)$ & 743 & 9837185 & $7.6(7.0,8.1)$ & 347 & 4981431 & $7.0(6.3,7.7)$ & $1.0(0.9,1.1)$ & $0.9(0.8,1.0)$ \\
\hline Males-younger & 512 & 4269677 & $12.1(11.1,13.2)$ & 486 & 4239677 & $11.5(10.5,12.5)$ & 224 & 2147349 & $10.4(9.2,11.9)$ & $0.9(0.8,1.1)$ & $0.9(0.7,1.0)$ \\
\hline Males-older & 100 & 484997 & $20.6(16.9,25.1)$ & 108 & 484997 & $22.3(18.4,26.9)$ & 49 & 246643 & $19.9(15.0,26.3)$ & $1.1(0.8,1.4)$ & $1.0(0.7,1.4)$ \\
\hline Females-younger & 131 & 4362038 & $3.0(2.5,3.6)$ & 125 & 4362038 & $2.9(2.4,3.4)$ & 61 & 2206899 & $2.8(2.2,3.6)$ & $1.0(0.7,1.2)$ & $0.9(0.7,1.2)$ \\
\hline Females-older & 24 & 750473 & $3.2(2.1,4.8)$ & 24 & 750473 & $3.2(2.1,4.8)$ & 13 & 380540 & $3.4(2.0,5.9)$ & $1.0(0.6,1.8)$ & $1.1(0.5,2.1)$ \\
\hline \multicolumn{12}{|l|}{ Ragweed season } \\
\hline All suicides & 424 & 3681222 & $11.5(10.5,12.7)$ & 743 & 6091065 & $12.2(11.4,13.1)$ & 644 & 5924903 & $10.9(10.1,11.7)$ & $1.1(0.9,1.2)$ & $0.9(0.8,1.1)$ \\
\hline Males-younger & 273 & 1598417 & $17.1(15.2,19.2)$ & 465 & 2636818 & $17.6(16.1,19.3)$ & 425 & 2565514 & $16.6(15.1,18.2)$ & $1.0(0.9,1.2)$ & $1.0(0.8,1.1)$ \\
\hline Males-older & 56 & 176297 & $31.8(24.4,41.3)$ & 117 & 297432 & $39.3(32.8,47.2)$ & 74 & 286098 & $25.9(20.6,32.5)$ & $1.2(0.9,1.7)$ & $0.8(0.6,1.2)$ \\
\hline Females-younger & 83 & 1627896 & $5.1(4.1,6.3)$ & 144 & 2701889 & $5.3(4.5,6.3)$ & 127 & 2628700 & $4.8(4.1,5.7)$ & $1.0(0.8,1.4)$ & $0.9(0.7,1.2)$ \\
\hline Females—older & 12 & 278611 & $4.3(2.4,7.6)$ & 17 & 454926 & $3.7(2.3,6.0)$ & 18 & 444591 & $4.0(2.6,6.4)$ & $0.9(0.4,1.8)$ & $0.9(0.5,2.0)$ \\
\hline Nonviolent suicides & 70 & 3681221 & $1.9(1.5,2.4)$ & 124 & 6091065 & $2.0(1.7,2.4)$ & 120 & 5924903 & $2.0(1.7,2.4)$ & $1.1(0.8,1.4)$ & $1.1(0.8,1.4)$ \\
\hline Males-younger & 45 & 1598417 & $2.8(2.1,3.8)$ & 66 & 2636818 & $2.5(2.0,3.2)$ & 68 & 2565514 & $2.7(2.1,3.4)$ & $0.9(0.6,1.3)$ & $0.9(0.6,1.4)$ \\
\hline Males-older & 5 & 176297 & $2.8(1.2,6.8)$ & 17 & 297432 & $5.7(3.6,9.2)$ & 13 & 286098 & $4.5(2.6,7.8)$ & $2.0(0.7,5.5)$ & $1.6(0.6,4.5)$ \\
\hline Females-younger & 17 & 1627896 & $1.0(0.6,1.7)$ & 36 & 2701889 & $1.3(1.0,1.8)$ & 35 & 2628700 & $1.3(1.0,1.9)$ & $1.3(0.7,2.3)$ & $1.3(0.7,2.3)$ \\
\hline Females-older & 3 & 278611 & $1.1(0.3,3.3)$ & 5 & 454926 & $1.1(0.5,2.6)$ & 4 & 444591 & $0.9(0.3,2.4)$ & $1.0(0.2,4.3)$ & $0.8(0.2,3.7)$ \\
\hline Violen & 332 & 3681221 & $9.0(8.1,10.0)$ & 558 & 091065 & $9.2(8.4,10.0$ & 490 & 5924903 & $8.3(7.6,9.0)$ & $1.0(0.9,1.2)$ & $0.9(0.8,1.1)$ \\
\hline Males-younger & 216 & 1598417 & $13.5(11.8,15.4)$ & 368 & 2636818 & $14.0(12.6,15.5)$ & 344 & 2565514 & $13.4(12.1,14.9)$ & $1.0(0.9,1.2)$ & $1.0(0.8,1.2)$ \\
\hline Males—older & 50 & 176297 & $28.4(21.5,37.4)$ & 94 & 297432 & $31.6(25.8,38.7)$ & 58 & 286098 & $20.3(15.7,26.2)$ & $1.1(0.8,1.6)$ & $0.7(0.5,1.0)$ \\
\hline Females-younger & 58 & 1627896 & $3.6(2.8,4.6)$ & 85 & 2701889 & $3.1(2.5,3.9)$ & 76 & 2628700 & $2.9(2.3,3.6)$ & $0.9(0.6,1.2)$ & $0.8(0.6,1.1)$ \\
\hline Females-older & 8 & 278611 & $2.9(1.4,5.7)$ & 11 & 454926 & $2.4(1.3,4.4)$ & 12 & 444591 & $2.7(1.5,4.8)$ & $0.8(0.3,2.1)$ & $0.9(0.4,2.3)$ \\
\hline
\end{tabular}

${ }^{a}$ Rates per 100000 person-years; $\mathrm{CI}=$ confidence interval; $\mathrm{RR}=$ relative rates.

Bold represents statistically significant. 
tree taxa. An important additional concern is that very few nonviolent suicides were recorded in ragweed season, and since the classification comes from vital statistics data, misclassification could have a large impact on our findings for cells with few events.

Several key factors necessarily remain unmeasured in our data, such as allergen and light exposure, and medical and psychiatric history. While our result may have been confounded by a number of biological and psychosocial factors (such as impact of feeling sick), acting during the allergy season on individuals and their social support systems, the drug treatments of allergies are particularly relevant. Specifically, overthe-counter medications containing pseudoephedrine may worsen prosuicidal factors such as insomnia, agitation, anxiety, and impulsivity, and antihistamines may cause somnolence and cognitive disturbance. Systemic corticosteroids used for more severe symptoms can precipitate depressive, mixed, or manic episodes. Other confounding seasonal factors that peak during late winter and early spring, such as certain viral infections (corona viruses, influenza), ${ }^{8}$ may induce inflammation and increased cytokine production in early spring. Alternatively, late winter and early spring decrements in immune defenses ${ }^{8}$ against neurotropic pathogens ${ }^{9}$ could also result in seasonal decompensation of mood disorders.

Nevertheless, the link between the activation of the immune system with depression and possibly suicide may be directly related to the increased expression of cytokines during immune activation. Several mechanisms that may explain this association are currently under investigation. Further studies are necessary to define environmental factors, which, in interaction with genetic and developmental vulnerability and resilience, may contribute to the seasonal peaks of suicide. This research may contribute to the stressdiathesis concept of depression-induced suicide, ${ }^{10}$ open new perspectives regarding the environmental precipitants of suicidal behavior, and lead to the development of novel therapeutic approaches to prevent suicide.

\section{Acknowledgements}

We would like to thank Dr Esther Sternberg for essential theoretical as well logistical help at the initiation of this study and comments on an earlier draft of the manuscript, Dr Dean Metcalfe for important early insights in seasonal allergy, which helped with the conceptual framework of the study design, Dr John Bartko for initial statistical advice, and to Dr Faheem Syed for help with pollen data management. We are also grateful to R Mittendorf and Drs Katayoun Khosravani and Darshita Shah for their help with sunlight data management. Finally, we would like thank those members of American Academy of Allergy, Asthma, \& Immunology who generously donate their time and expertise in participating in the Aeroallergen Network. The study was supported by DC-Department of Mental Health, Washington, DC (Dr Postolache, Principal Investigator).
TT Postolache ${ }^{1,2}$, JW Stiller ${ }^{1,2}$, R Herrell $^{3}$, MA Goldstein ${ }^{2}$, SS Shreeram ${ }^{2}$, R Zebrak ${ }^{2}$, CM Thrower ${ }^{2}$, J Volkov ${ }^{2}$, MJ No², I Volkov' ${ }^{2}$ KJ Rohan ${ }^{4}$, J Redditt ${ }^{2}$, M Parmar ${ }^{2}$, F Mohyuddin ${ }^{2}$, C Olsen ${ }^{5}$, M Moca ${ }^{2}$, LH Tonelli ${ }^{6}$, K Merikangas $^{3}$ and HD Komarow ${ }^{1,7}$

${ }^{1}$ Mood and Anxiety Disorder Program, Department of Psychiatry, University of Maryland School of Medicine, Baltimore, MD, USA; ${ }^{2} D C$ DMH, St Elizabeth's Hospital Psychiatry Residency Training Program, Washington, DC, USA; ${ }^{3}$ Section on Developmental Genetic Epidemiology, the National Institute of Mental Health, the National Institutes of Health, Department of Health and Human Services, Bethesda, MD, USA; ${ }^{4}$ Department of Medical Psychology, Uniform Services University, Bethesda, MD, USA; ${ }^{5}$ Department of Preventive Medicine and Biometrics, Uniform Services University of the Health Services, Bethesda, MD, USA; ${ }^{6}$ Section on Neuroendocrine Immunology and Behavior, the National Institute of Mental Health, the National Institutes of Health, Department of Health and Human Services, Bethesda, MD, USA; ${ }^{7}$ Genetics and Genomics Branch, National Institute of Arthritis and Musculoskeletal and Skin Diseases, the National Institutes of Health, Department of Health and Human Services, Bethesda, MD, USA

Correspondence should be addressed to Dr TT Postolache, Mood and Anxiety Program, Department of Psychiatry, University of Maryland School of Medicine, 685 West Baltimore Street, MSTF Building Room 502, Baltimore, MD, 21201, USA.

E-mail: tpostolache@psych.umaryland.edu

1 Hakko H et al. Acta Psychiatr Scand 1998; 98: 92-97.

2 Reichenberg A et al. Arch Gen Psychiatry 2001; 58: 445-452.

3 Capuron L, Dantzer R. Brain Behav Immun 2003; 17(Suppl 1): S119-S124.

4 Licinio J, Wong ML. Mol Psychiatry 1999; 4: 317-327.

5 Wichers M, Maes M. Int J Neuropsychopharmacol 2002; 5 375-388.

6 Maier SF. Brain Behav Immun 2003; 17: 69-85.

7 Timonen M et al. Mol Psychiatry 2003; 8: 738-744.

8 Nelson RJ et al. Seasonal Patterns of Stress, Immune Function, and Disease, 1st edn. Press Syndicate of the University of Cambridge, Cambridge University Press: Cambridge, UK, 2002.

9 Bode L, Ludwig H. Clin Microbiol Rev 2003; 16: 534-545. 10 Mann JJ. Nat Rev Neurosci 2003; 4: 819-828.

\section{Absence of psychosis may influence linkage results for bipolar disorder}

Molecular Psychiatry (2005) 10, 235-237.

doi:10.1038/sj.mp.4001623

Published online 30 November 2004

SIR-Dissection of the clinical phenotype into more homogeneous subtypes can enhance the prospects of linkage analysis. In this study, we report linkage results for bipolar disorder (BP) without psychosis 